\title{
RADIATION DOSE-VOLUME EFFECTS IN THE BRAIN
}

\author{
Yaacov Richard Lawrence, M.R.C.P. ${ }^{\star}$, X. Allen Li, Ph.D. ${ }^{\dagger}$, Issam el Naqa, Ph.D. ${ }^{\ddagger}$, Carol A. \\ Hahn, M.D.§, Lawrence B. Marks, M.D. I, Thomas E. Merchant, D.O., Ph.D.I, and Adam P. \\ Dicker, M.D., Ph.D.* \\ *Department of Radiation Oncology, Thomas Jefferson University, Philadelphia, PA \\ tDepartment of Radiation Oncology, Medical College of Wisconsin, Milwaukee, WI \\ FDepartment of Radiation Oncology, Washington University School of Medicine, St. Louis, MO \\ §Department of Radiation Oncology, Duke University Medical Center, Durham, NC \\ IDepartment of Radiation Oncology, University of North Carolina, Chapel Hill, NC \\ "Department of Radiation Oncology, St. Jude Children's Research Hospital, Memphis, TN
}

\begin{abstract}
We have reviewed the published data regarding radiotherapy (RT)-induced brain injury. Radiation necrosis appears a median of 1-2 years after RT; however, cognitive decline develops over many years. The incidence and severity is dose and volume dependent and can also be increased by chemotherapy, age, diabetes, and spatial factors. For fractionated RT with a fraction size of $<2.5$ $\mathrm{Gy}$, an incidence of radiation necrosis of $5 \%$ and $10 \%$ is predicted to occur at a biologically effective dose of $120 \mathrm{~Gy}$ (range, 100-140) and $150 \mathrm{~Gy}$ (range, 140-170), respectively. For twicedaily fractionation, a steep increase in toxicity appears to occur when the biologically effective dose is $>80 \mathrm{~Gy}$. For large fraction sizes ( $\geq 2.5 \mathrm{~Gy}$ ), the incidence and severity of toxicity is unpredictable. For single fraction radiosurgery, a clear correlation has been demonstrated between the target size and the risk of adverse events. Substantial variation among different centers' reported outcomes have prevented us from making toxicity-risk predictions. Cognitive dysfunction in children is largely seen for whole brain doses of $\geq 18 \mathrm{~Gy}$. No substantial evidence has shown that RT induces irreversible cognitive decline in adults within 4 years of RT.
\end{abstract}

\section{Keywords}

Radiotherapy; stereotactic radiosurgery; brain; tolerance; side effects

\section{CLINICAL SIGNIFICANCE}

Radiotherapy (RT) plays an important role in the curative and palliative treatment of patients with primary and metastatic brain tumors. Primary brain tumors account for $22 \%$ of tumors in those $<18$ years of age. Brain metastases occur in $\approx 30 \%$ of patients diagnosed with solid tumors, afflicting $\approx 170,000$ Americans annually. The acute and late effects of RT on the brain are common and represent a significant source of morbidity. Such morbidity is particularly troubling in patients with baseline tumor-related dysfunction. In addition, the

\footnotetext{
Copyright $(92010$ Elsevier Inc.

Reprint requests to: Yaacov Richard Lawrence, M.R.C.P., Department of Radiation Oncology, Jefferson Medical College of Thomas Jefferson University, Bodine Cancer Center, 111 S. 11th St., Philadelphia, PA 19107. Tel: (215) 955-6700; Fax: (215) 955-0412; richard.lawrence@jefferson.edu.

Conflict of interest: none.
} 
radiation fields used to treat the upper aerodigestive track (e.g., pharynx and nasal cavities) often include a portion of the brain.

\section{ENDPOINTS}

The acute side effects of RT to the brain include nausea, vomiting, and headache; vertigo and seizures are less frequent. These symptoms are transient and generally respond to medication.

The present report summarizes the dose-volume predictors for the principal late side effects of RT to the brain: radiation necrosis and cognitive deterioration. A biopsy is rarely performed to confirm suspected radiation necrosis. The working definition used by most of the studies listed in Tables 1 and 2 was "new symptoms with suggestive radiologic findings."

However, most investigators have reported their late toxicity rates as crude numbers according to the number of patients treated rather than the number at risk (i.e., the survivors). This method understates the risk, because some subjects will have died before the toxicity has had a chance to develop. The actuarial rates have rarely been discussed. Surgery, chemotherapy, steroids, antiepileptic agents, and opioids impair neurologic and cognitive function, further confounding the interpretation of suspected RT toxicity.

\section{CHALLENGES DEFINING VOLUMES}

There is little disagreement regarding image segmentation of the entire brain, and little intraor interfraction movement occurs. However, segmenting the brain subregions is challenging (e.g., the superior boundary of the brain stem). Currently the utility of subregion definition is unclear.

\section{REVIEW OF DOSE-VOLUME DATA}

\section{Radiation necrosis}

For radiosurgery, the incidence of necrosis depends on the dose, volume, and region irradiated (1-10) (Table 1 and Fig. 1). The Radiation Therapy Oncology Group conducted a dose-escalation study that sought to define the maximal dose for targets of different sizes; all subjects had previously undergone whole brain irradiation. The maximal tolerated dose for targets 31-40 mm in diameter was $15 \mathrm{~Gy}$, and for targets $21-30 \mathrm{~mm}$ in diameter, it was 18 Gy. For targets $<20 \mathrm{~mm}$, the maximal tolerated dose was $>24 \mathrm{~Gy} \mathrm{(11).} \mathrm{The} \mathrm{volume} \mathrm{of} \mathrm{brain}$ receiving $\geq 12$ Gy has been shown to correlate with both the incidence of radiation necrosis and asymptomatic radiologic changes (Table 1).

The large variation in absolute complication rates among studies (Fig. 1) is difficult to comprehend, but it might relate to differences in the definitions of the volume and toxicity, the avoidance of critical structures, and the type and length of clinical follow-up.

For fractionated RT, the relationship between the radiation dose and radiation necrosis for partial brain irradiation is presented in Table $2(12-19)$ and Fig. 2, segregated by the fractionation scheme. Different fractionation schemes were compared using the biologically effective dose (BED) (20), with an $a / \beta$ ratio of 3 . For standard fractionation, a doseresponse relationship exists, such that an incidence of side effects of $5 \%$ and $10 \%$ occur at a BED of 120 Gy (range, 100-140) and 150 Gy (range, 140-170), respectively (corresponding to 72 Gy [range, 60-84] and 90 Gy [range, 84-102] in 2-Gy fractions). For twice-daily fractionation, a steep increase in toxicity appears to occur when the BED is $>80 \mathrm{~Gy}$. For daily large fraction sizes $(>2.5 \mathrm{~Gy})$, the incidence and severity of toxicity is unpredictable. 
The reader is cautioned against overinterpreting the data presented in Fig. 2, which was created from a heterogeneous data pool (i.e., different target volumes, endpoints, sample sizes, and brain regions). No evidence has shown that children are especially at risk of radiation necrosis $(21,22)$.

\section{Neurocognitive function in children}

The neurocognitive effects of cranial RT in children have been studied in several settings. With central nervous system prophylaxis for acute lymphoblastic leukemia, the addition of $24 \mathrm{~Gy}$ radiation to the whole brain (to a chemotherapy regimen) has been associated with a median 13-point intelligence quotient reduction at 5 years after RT and poorer academic achievement and self-image, and greater psychological distress (23) at 15 years after RT. The reported toxicities have been lower (or not detected) when 14-18 Gy was used (24-26).

In medulloblastoma, the post-RT intelligence quotients were $10-15$ points better after a whole brain dose of 23.4 Gy vs. 36 Gy $(27,28)$. Others (29), but not all $(30,31)$, have also noted a dose response in the 18-36-Gy range. Differences between the studies can be explained by the inability of small studies to overcome the complex interactions among dose, volume, patient age, and follow-up length. Merchant et al. (32) has suggested that different regions of the brain, particularly the supratentorial area, are important in the development of RT-associated cognitive decline.

\section{Neurocognitive functioning in adults}

The evidence for RT-induced neurocognitive injury in adults is weak. Irreversible cognitive side effects were first highlighted in survivors who had undergone whole brain RT in 3-6 Gy/fraction (33). Subsequently, cognitive dysfunction was found to be frequently present even before RT (34). Multiple studies have demonstrated improved cognitive function after RT, because of its antitumor effects (35-39). The results from randomized studies of "elective" whole brain RT (e.g., for lung small cell carcinoma) have been difficult to interpret because those not receiving RT have tended to develop more brain metastases. In one adult study, learning impairment did not develop until 5 years after RT (40); however, few studies have followed up patients for this long.

Several studies have compared the cognitive function of patients who underwent RT with that of those who did not. Four studies with a follow-up of $\mathcal{s}$ years found no difference (34, 41-43). However, the two studies with $\geq 5$ years of follow-up noted negative cognitive effects of RT; most of these patients had undergone partial brain RT $(44,45)$. The total doses were 56 and $60 \mathrm{~Gy}$; only those receiving fraction sizes $>2$ Gy showed cognitive decline. Two randomized studies of high- vs. low-dose partial brain irradiation failed to discern a difference in neurocognitive outcome $(46,47)$; however, an insensitive instrument was used.

Two small studies suggested that whole brain RT is more detrimental than focal RT $(48,49)$. These findings were not confirmed by a randomized trial comparing radiosurgery and radiosurgery combined with whole brain RT, however this study used an insensitive instrument and had a short follow-up period (50).

Thus, very limited evidence is available to show that brain RT in 2-Gy fractions causes irreversible cognitive decline in adults.

\section{FACTORS AFFECTING RISK}

The radiation dose, fraction size, and volume are the major variables that influence the development of radiation necrosis. Although location does not influence the susceptibility to 
radiation necrosis, necrosis is far more likely to be symptomatic in certain areas (e.g., corpus callosum and brain stem) (51). Other suggested risk factors for radiation necrosis include chemotherapy use, lower conformality index, shorter overall treatment time, older age, and diabetes mellitus $(12,15,30)$.

Young age is the most important risk factor for neurocognitive decline in children undergoing cranial RT $(29,31,52)$. Other risk factors include female gender, NF-1 mutation, extent of surgical resection, hydrocephalus, concomitant chemotherapy (especially methotrexate), location, and volume of brain irradiated (31,53-57). An excellent review can be found in the report by Duffner (58).

The risk factors for neurocognitive decline in adults might include the volume irradiated (48, 49), large fraction size (44), and longer interval after treatment (40).

\section{MATHEMATICAL/BIOLOGIC MODELS}

The linear-quadratic model has been used to model radiation necrosis in the brain after fractionated RT $(12,13,20)$. The $a / \beta$ ratio for the normal brain has been estimated to be 2.9 (13).

For radiosurgery, a variety of models have been suggested. All are highly simplified and ignore many relevant variables, and none has been adequately validated.

\section{SPECIAL SITUATIONS}

Re-irradiation is frequently performed in the brain. A meta-analysis of brain re-irradiation (interval between courses, 3-55 months) found no cases of necrosis when the total radiation dose was $<100 \mathrm{~Gy}$ (normalized to $2 \mathrm{~Gy} /$ fraction; $a / \beta$ ratio, 2) (59).

Unlike other settings, in primary central nervous system lymphoma, RT (to $\approx 40 \mathrm{~Gy}$ ) has been associated with cognitive decline, especially in those $>60$ years old $(60,61)$. The heightened sensitivity of this population to irradiation might be explained by the tumor's highly diffuse, angiocentric growth pattern and that most patients receive high-dose methotrexate, a potent neurotoxin. As a result, upfront full-dose RT is now often avoided in elderly patients with this disease. A lower radiation dose of $23.4 \mathrm{~Gy}$ might be safe even in older patients (62).

\section{RECOMMENDED DOSE-VOLUME LIMITS}

The constraints presented in the following paragraphs are the best estimates determined from the available data; however, high-level evidence is lacking. The constraints should be used with appropriate caution and interpreted within the clinical context.

\section{Fractionated RT to partial brain}

For standard fractionation, a $5 \%$ and $10 \%$ risk of symptomatic radiation necrosis is predicted to occur at a BED of 120 Gy (range, 100-140) and 150 Gy (range, 140-170), respectively (corresponding to 72 Gy [range, 60-84] and $90 \mathrm{~Gy}$ [range, 84-102] in 2-Gy fractions). The brain is especially sensitive to fraction sizes $>2$ Gy and, surprisingly, twice-daily RT.

Cognitive changes occur in children after $\geq 18$ Gy to the entire brain. The effect of irradiation on the cognitive performance of adults is less well defined.

Emami's original estimate for fractionated partial brain RT (5\% risk at 5 years for one-third brain, $60 \mathrm{~Gy}$ ) appears to be overly conservative. We have concluded that the $5 \%$ risk at 5 
years of the partial brain for normally fractionated RT is 72 Gy (range, 60-84). We emphasize that for most cancers, there is no clinical indication for giving fractionated RT $>60 \mathrm{~Gy}$ and that, in some scenarios, an incidence of $1-5 \%$ radiation necrosis at 5 years would be unacceptably high.

\section{Radiosurgery}

The risk of complications increases with the size of the target volume. Toxicity increases rapidly once the volume of the brain exposed to $>12 \mathrm{~Gy}$ is $>5-10 \mathrm{~cm}^{3}$. Eloquent areas of the brain (brain stem, corpus callosum) require more stringent limits. The substantial variation between the reported treatment parameters and outcomes from different centers has prevented us from making precise toxicity risk predictions.

\section{FUTURE TOXICITY STUDIES}

Modern imaging modalities (e.g., magnetic resonance imaging perfusion and spectroscopy, positron emission tomography) can detect damage before routine computed tomography or magnetic resonance imaging and symptom development (63-65). Hahn et al. (66) detected metabolic changes in normal brain that had undergone $>40 \mathrm{~Gy}$ and correlated these with neurocognitive effects. Future studies should aim to link early imaging changes with clinically relevant endpoints, facilitating rapid and quantitative estimates of treatmentinduced toxicity.

The effect of chemotherapy and newer targeted biologic agents on the incidence and severity of radiation necrosis and cognitive outcomes should be systematically addressed.

Higher functions require input from spatially disparate brain regions, producing a complex interaction between the radiation dose distribution and neurologic outcomes. A recent study demonstrated the utility of diffusion-tensor tractography in assessing the tolerance thresholds for different neurologic tracts (67).

The designation and avoidance of "key" areas of the brain is needed. For instance, the role of the hippocampus in memory formation has recently been emphasized, encouraging clinicians to limit the radiation dose to it (62). The efficacy of such approaches has not yet been proved. Also, a quick and sensitive test for neurocognitive function that can be included in clinical studies is needed.

The best method to obtain quality long-term follow-up data would be the creation of an international registry to gather and relate demographic factors, diagnoses, co-morbidities, baseline imaging findings, other treatment modalities, and the three-dimensional isodose distribution (with or without biospecimens) to outcomes. A National Cancer Institutesponsored institution such as the Radiation Therapy Oncology Group would be well suited for both data collection and analysis.

\section{TOXICITY SCORING}

The Common Terminology Criteria for Adverse Events, version 4.0, is recommended as a tool for scoring neurocognitive dysfunction. Long-term follow-up (e.g., $\geq 5$ years) might be necessary to detect neurologic/cognitive decline. Prospective RT studies should incorporate formal neurocognitive assessments. Future studies reporting RT brain toxicity should provide a clear definition of toxicity, detailed normal brain dose-volume information, the use of repeat RT and systemic treatments, and should report toxicity as an actuarial (as opposed to a crude) rate. We recommend adoption of the "volume receiving $12 \mathrm{Gy"}$ as the standard method of reporting the dose to the normal brain in radiosurgery procedures. The location should also be reported. 


\section{Acknowledgments}

Y. R. Lawrence is supported by The ASCO Cancer Foundation Young Investigator Award. Any opinions, findings, and conclusions expressed in this material are those of the author(s) and do not necessarily reflect those of the American Society of Clinical Oncology or The ASCO Cancer Foundation. L. B. Marks is supported by NIH R01 69579 and the Lance Armstrong Foundation.

A. P. Dicker is supported by National Institutes of Health Grant CA10663, Tobacco Research Settlement Fund (State of Pennsylvania), and the Christine Baxter Fund.

\section{References}

1. Lax I, Karlsson B. Prediction of complications in gamma knife radiosurgery of arteriovenous malformation. Acta Oncol. 1996; 35:49-55. [PubMed: 8619940]

2. Voges J, Treuer H, Sturm V, et al. Risk analysis of linear accelerator radiosurgery. Int J Radiat Oncol Biol Phys. 1996; 36:1055-1063. [PubMed: 8985027]

3. Flickinger JC, Kondziolka D, Pollock BE, et al. Complications from arteriovenous malformation radiosurgery: Multivariate analysis and risk modeling. Int J Radiat Oncol Biol Phys. 1997; 38:485490. [PubMed: 9231670]

4. Miyawaki L, Dowd C, Wara W, et al. Five year results of LINAC radiosurgery for arteriovenous malformations: Outcome for large AVMS. Int J Radiat Oncol Biol Phys. 1999; 44:1089-1106. [PubMed: 10421543]

5. Chin LS, Ma L, DiBiase S. Radiation necrosis following gamma knife surgery: A case-controlled comparison of treatment parameters and long-term clinical follow up. J Neurosurg. 2001; 94:899_ 904. [PubMed: 11409517]

6. Nakamura JL, Verhey LJ, Smith V, et al. Dose conformity of gamma knife radiosurgery and risk factors for complications. Int J Radiat Oncol Biol Phys. 2001; 51:1313-1319. [PubMed: 11728692]

7. Barker FG II, Butler WE, Lyons S, et al. Dose-volume prediction of radiation-related complications after proton beam radio-surgery for cerebral arteriovenous malformations. J Neurosurg. 2003; 99:254-263. [PubMed: 12924697]

8. Friedman WA, Bova FJ, Bollampally S, et al. Analysis of factors predictive of success or complications in arteriovenous malformation radiosurgery. Neurosurgery. 2003; 52:296-307. [PubMed: 12535357]

9. Varlotto JM, Flickinger JC, Niranjan A, et al. Analysis of tumor control and toxicity in patients who have survived at least one year after radiosurgery for brain metastases. Int J Radiat Oncol Biol Phys. 2003; 57:452-464. [PubMed: 12957257]

10. Korytko T, Radivoyevitch T, Colussi V, et al. 12 Gy gamma knife radiosurgical volume is a predictor for radiation necrosis in non-AVM intracranial tumors. Int J Radiat Oncol Biol Phys. 2006; 64:419-424. [PubMed: 16226848]

11. Shaw E, Scott C, Souhami L, et al. Single dose radiosurgical treatment of recurrent previously irradiated primary brain tumors and brain metastases: Final report of RTOG protocol 90-05. Int J Radiat Oncol Biol Phys. 2000; 47:291-298. [PubMed: 10802351]

12. Lee AW, Kwong DL, Leung SF, et al. Factors affecting risk of symptomatic temporal lobe necrosis: Significance of fractional dose and treatment time. Int J Radiat Oncol Biol Phys. 2002; 53:75-85. [PubMed: 12007944]

13. Lee AW, Foo W, Chappell R, et al. Effect of time, dose, and fractionation on temporal lobe necrosis following radiotherapy for nasopharyngeal carcinoma. Int J Radiat Oncol Biol Phys. 1998; 40:35-42. [PubMed: 9422555]

14. Corn BW, Yousem DM, Scott CB, et al. White matter changes are correlated significantly with radiation dose: Observations from a randomized dose-escalation trial for malignant glioma (Radiation Therapy Oncology Group 83-02). Cancer. 1994; 74:2828-2835. [PubMed: 7954244]

15. Ruben JD, Dally M, Bailey M, et al. Cerebral radiation necrosis: Incidence, outcomes, and risk factors with emphasis on radiation parameters and chemotherapy. Int J Radiat Oncol Biol Phys. 2006; 65:499-508. [PubMed: 16517093] 
16. Shaw E, Arusell R, Scheithauer B, et al. Prospective randomized trial of low-versus high-dose radiation therapy in adults with supratentorial low-grade glioma: Initial report of a North Central Cancer Treatment Group/Radiation Therapy Oncology Group/Eastern Cooperative Oncology Group study. J Clin Oncol. 2002; 20:2267-2276. [PubMed: 11980997]

17. Murray KJ, Scott C, Greenberg HM, et al. A randomized phase III study of accelerated hyperfractionation versus standard in patients with unresected brain metastases: A report of the Radiation Therapy Oncology Group (RTOG) 9104. Int J Radiat Oncol Biol Phys. 1997; 39:571574. [PubMed: 9336134]

18. Sause WT, Scott C, Krisch R, et al. Phase I/II trial of accelerated fractionation in brain metastases RTOG 85-28. Int J Radiat Oncol Biol Phys. 1993; 26:653-657. [PubMed: 8330997]

19. Jen YM, Hsu WL, Chen CY, et al. Different risks of symptomatic brain necrosis in NPC patients treated with different altered fractionated radiotherapy techniques. Int J Radiat Oncol Biol Phys. 2001; 51:344-348. [PubMed: 11567807]

20. Fowler JF. The linear-quadratic formula and progress in fractionated radiotherapy. Br J Radiol. 1989; 62:679-694. [PubMed: 2670032]

21. Smyth MD, Sneed PK, Ciricillo SF, et al. Stereotactic radiosurgery for pediatric intracranial arteriovenous malformations: The University of California at San Francisco experience. J Neurosurg. 2002; 97:48-55. [PubMed: 12134932]

22. Tanaka T, Kobayashi T, Kida Y, et al. Comparison between adult and pediatric arteriovenous malformations treated by gamma knife radiosurgery. Stereotact Funct Neurosurg. 1996; 66(Suppl 1):288-295. [PubMed: 9032871]

23. Hill JM, Kornblith AB, Jones D, et al. A comparative study of the long term psychosocial functioning of childhood acute lymphoblastic leukemia survivors treated by intrathecal methotrexate with or without cranial radiation. Cancer. 1998; 82:208-218. [PubMed: 9428499]

24. Waber DP, Turek J, Catania L, et al. Neuropsychological outcomes from a randomized trial of triple intrathecal chemotherapy compared with 18 Gy cranial radiation as CNS treatment in acute lymphoblastic leukemia: Findings from Dana-Farber Cancer Institute ALL Consortium Protocol 95-01. J Clin Oncol. 2007; 25:4914-4921. [PubMed: 17971588]

25. Moore IM, Kramer JH, Wara W, et al. Cognitive function in children with leukemia. Effect of radiation dose and time since irradiation. Cancer. 1991; 68:1913-1917. [PubMed: 1913542]

26. Smibert E, Anderson V, Godber T, et al. Risk factors for intellectual and educational sequelae of cranial irradiation in childhood acute lymphoblastic leukaemia. Br J Cancer. 1996; 73:825-830. [PubMed: 8611389]

27. Mulhern RK, Kepner JL, Thomas PR, et al. Neuropsychologic functioning of survivors of childhood medulloblastoma randomized to receive conventional or reduced-dose craniospinal irradiation: A Pediatric Oncology Group study. J Clin Oncol. 1998; 16:1723-1728. [PubMed: 9586884]

28. Mulhern RK, Fairclough D, Ochs J. A prospective comparison of neuropsychologic performance of children surviving leukemia who received 18-Gy, 24-Gy, or no cranial irradiation. J Clin Oncol. 1991; 9:1348-1356. [PubMed: 2072138]

29. Jannoun L, Bloom HJ. Long-term psychological effects in children treated for intracranial tumors. Int J Radiat Oncol Biol Phys. 1990; 18:747-753. [PubMed: 2323966]

30. Smith MC, Ryken TC, Buatti JM. Radiotoxicity after conformal radiation therapy for benign intracranial tumors. Neurosurg Clin North Am. 2006; 17:169-180. vii.

31. Bleyer WA, Fallavollita J, Robison L, et al. Influence of age, sex, and concurrent intrathecal methotrexate therapy on intellectual function after cranial irradiation during childhood: A report from the Children's Cancer Study Group. Pediatr Hematol Oncol. 1990; 7:329-338. [PubMed: 2268533]

32. Merchant TE, Kiehna EN, Li C, et al. Modeling radiation dosimetry to predict cognitive outcomes in pediatric patients with CNS embryonal tumors including medulloblastoma. Int J Radiat Oncol Biol Phys. 2006; 65:210-221. [PubMed: 16472938]

33. DeAngelis LM, Delattre JY, Posner JB. Radiation-induced dementia in patients cured of brain metastases. Neurology. 1989; 39:789-796. [PubMed: 2725874] 
34. Gregor A, Cull A, Stephens RJ, et al. for theUnited Kingdom Coordinating Committee for Cancer Research (UKCCCR) and the European Organization for Research and Treatment of Cancer (EORTC). Prophylactic cranial irradiation is indicated following complete response to induction therapy in small cell lung cancer: Results of a multicentre randomised trial. Eur J Cancer. 1997; 33:1752-1758. [PubMed: 9470828]

35. Steinvorth S, Wenz F, Wildermuth S, et al. Cognitive function in patients with cerebral arteriovenous malformations after radiosurgery: Prospective long-term follow-up. Int J Radiat Oncol Biol Phys. 2002; 54:1430-1437. [PubMed: 12459366]

36. Steinvorth S, Welzel G, Fuss M, et al. Neuropsychological outcome after fractionated stereotactic radiotherapy (FSRT) for base of skull meningiomas: A prospective 1-year follow-up. Radiother Oncol. 2003; 69:177-182. [PubMed: 14643955]

37. Khuntia D, Brown P, Li J, et al. Whole-brain radiotherapy in the management of brain metastasis. J Clin Oncol. 2006; 24:1295-1304. [PubMed: 16525185]

38. Armstrong C, Ruffer J, Corn B, et al. Biphasic patterns of memory deficits following moderatedose partial-brain irradiation: Neuropsychologic outcome and proposed mechanisms. J Clin Oncol. 1995; 13:2263-2271. [PubMed: 7666084]

39. Li J, Bentzen SM, Renschler M, et al. Regression after whole-brain radiation therapy for brain metastases correlates with survival and improved neurocognitive function. J Clin Oncol. 2007; 25:1260-1266. [PubMed: 17401015]

40. Armstrong CL, Hunter JV, Ledakis GE, et al. Late cognitive and radiographic changes related to radiotherapy: Initial prospective findings. Neurology. 2002; 59:40-48. [PubMed: 12105305]

41. Vigliani MC, Sichez N, Poisson M, et al. A prospective study of cognitive functions following conventional radiotherapy for supratentorial gliomas in young adults: 4-Year results. Int J Radiat Oncol Biol Phys. 1996; 35:527-533. [PubMed: 8655376]

42. Grosshans DR, Meyers CA, Allen PK, et al. Neurocognitive function in patients with small cell lung cancer: Effect of prophylactic cranial irradiation. Cancer. 2008; 112:589-595. [PubMed: 18098269]

43. Arriagada R, Le Chevalier T, Borie F, et al. Prophylactic cranial irradiation for patients with smallcell lung cancer in complete remission. J Natl Cancer Inst. 1995; 87:183-190. [PubMed: 7707405]

44. Klein M, Heimans J, Aaronson N, et al. Effect of radiotherapy and other treatment-related factors on mid-term to long-term cognitive sequelae in low-grade gliomas: A comparative study. Lancet. 2002; 360:1361-1368. [PubMed: 12423981]

45. Surma-aho O, Niemelä M, Vilkki J, et al. Adverse long-term effects of brain radiotherapy in adult low-grade glioma patients. Neurology. 2001; 56:1285-1290. [PubMed: 11376174]

46. Kiebert GM, Curran D, Aaronson NK, et al. for theEORTC Radiotherapy Co-operative Group. Quality of life after radiation therapy of cerebral low-grade gliomas of the adult: Results of a randomised phase III trial on dose response (EORTC trial 22844). Eur J Cancer. 1998; 34:19021909. [PubMed: 10023313]

47. Brown P. Effects of radiotherapy on cognitive function in patients with low-grade glioma measured by the Folstein Mini-Mental State Examination. J Clin Oncol. 2003; 21:2519-2524. [PubMed: 12829670]

48. Gregor A, Cull A, Traynor E, et al. Neuropsychometric evaluation of long-term survivors of adult brain tumours: Relationship with tumour and treatment parameters. Radiother Oncol. 1996; 41:5559. [PubMed: 8961368]

49. Kleinberg L, Wallner K, Malkin MG. Good performance status of long-term disease-free survivors of intracranial gliomas. Int J Radiat Oncol Biol Phys. 1993; 26:129-133. [PubMed: 8387064]

50. Aoyama H, Shirato H, Tago M, et al. Stereotactic radiosurgery plus whole-brain radiation therapy vs stereotactic radiosurgery alone for treatment of brain metastases: A randomized controlled trial. JAMA. 2006; 295:2483-2491. [PubMed: 16757720]

51. Flickinger JC, Kondziolka D, Maitz AH, et al. Analysis of neurological sequelae from radiosurgery of arteriovenous malformations: How location affects outcome. Int J Radiat Oncol Biol Phys. 1998; 40:273-278. [PubMed: 9457809] 
52. Merchant TE, Conklin HM, Wu S, et al. Late effects of conformal radiation therapy for pediatric patients with low-grade glioma: Prospective evaluation of cognitive, endocrine and hearing deficits. J Clin Oncol. 2009; 27:3691-3697. [PubMed: 19581535]

53. Brown RT, Madan-Swain A, Walco GA, et al. Cognitive and academic late effects among children previously treated for acute lymphocytic leukemia receiving chemotherapy as CNS prophylaxis. J Pediatr Psychol. 1998; 23:333-340. [PubMed: 9782681]

54. Meadows AT, Gordon J, Massari DJ, et al. Declines in IQ scores and cognitive dysfunctions in children with acute lymphocytic leukaemia treated with cranial irradiation. Lancet. 1981; 2:10151018. [PubMed: 6118478]

55. Ellenberg L, McComb JG, Siegel SE, et al. Factors affecting intellectual outcome in pediatric brain tumor patients. Neurosurgery. 1987; 21:638-644. [PubMed: 3696394]

56. Merchant TE, Lee H, Zhu J, et al. The effects of hydrocephalus on intelligence quotient in children with localized infratentorial ependymoma before and after focal radiation therapy. J Neurosurg. 2004; 101:159-168. [PubMed: 15835103]

57. Hirsch JF, Renier D, Czernichow P, et al. Medulloblastoma in childhood: Survival and functional results. Acta Neurochir (Wien). 1979; 48:1-15. [PubMed: 495234]

58. Duffner PK. Long-term effects of radiation therapy on cognitive and endocrine function in children with leukemia and brain tumors. Neurologist. 2004; 10:293-310. [PubMed: 15518596]

59. Mayer R, Sminia P. Reirradiation tolerance of the human brain. Int J Radiat Oncol Biol Phys. 2008; 70:1350-1360. [PubMed: 18037587]

60. Omuro AMP, Ben-Porat LS, Panageas KS, et al. Delayed neurotoxicity in primary central nervous system lymphoma. Arch Neurol. 2005; 62:1595-1600. [PubMed: 16216945]

61. Schlegel U, Pels H, Oehring R, et al. Neurologic sequelae of treatment of primary CNS lymphomas. J Neurooncol. 1999; 43:277-286. [PubMed: 10563434]

62. Shah GD, Yahalom J, Correa DD, et al. Combined immunochemotherapy with reduced wholebrain radiotherapy for newly diagnosed primary CNS lymphoma. J Clin Oncol. 2007; 25:47304735. [PubMed: 17947720]

63. Chan YL, Yeung DK, Leung SF, et al. Dynamic susceptibility contrast-enhanced perfusion MR imaging in late radiation-induced injury of the brain. Acta Neurochir Suppl. 2005; 95:173-175. [PubMed: 16463845]

64. Price SJ, Jena R, Green HA, et al. Early radiotherapy dose response and lack of hypersensitivity effect in normal brain tissue: A sequential dynamic susceptibility imaging study of cerebral perfusion. Clin Oncol (R Coll Radiol). 2007; 19:577-587. [PubMed: 17629467]

65. Fuss M, Wenz F, Scholdei R, et al. Radiation-induced regional cerebral blood volume (rCBV) changes in normal brain and low-grade astrocytomas: quantification and time and dose-dependent occurrence. Int J Radiat Oncol Biol Phys. 2000; 48:53-58. [PubMed: 10924971]

66. Hahn C, Zhou S, Raynor R, et al. Dose-dependent effects of radiation therapy on cerebral blood flow, metabolism, and neurocognitive dysfunction. Int J Radiat Oncol Biol Phys. 2009; 73:10821087. [PubMed: 18755558]

67. Maruyama K, Kamada K, Ota T, et al. Tolerance of pyramidal tract to gamma knife radiosurgery based on diffusion-tensor tractography. Int J Radiat Oncol Biol Phys. 2008; 70:1330-1335. [PubMed: 17935904] 


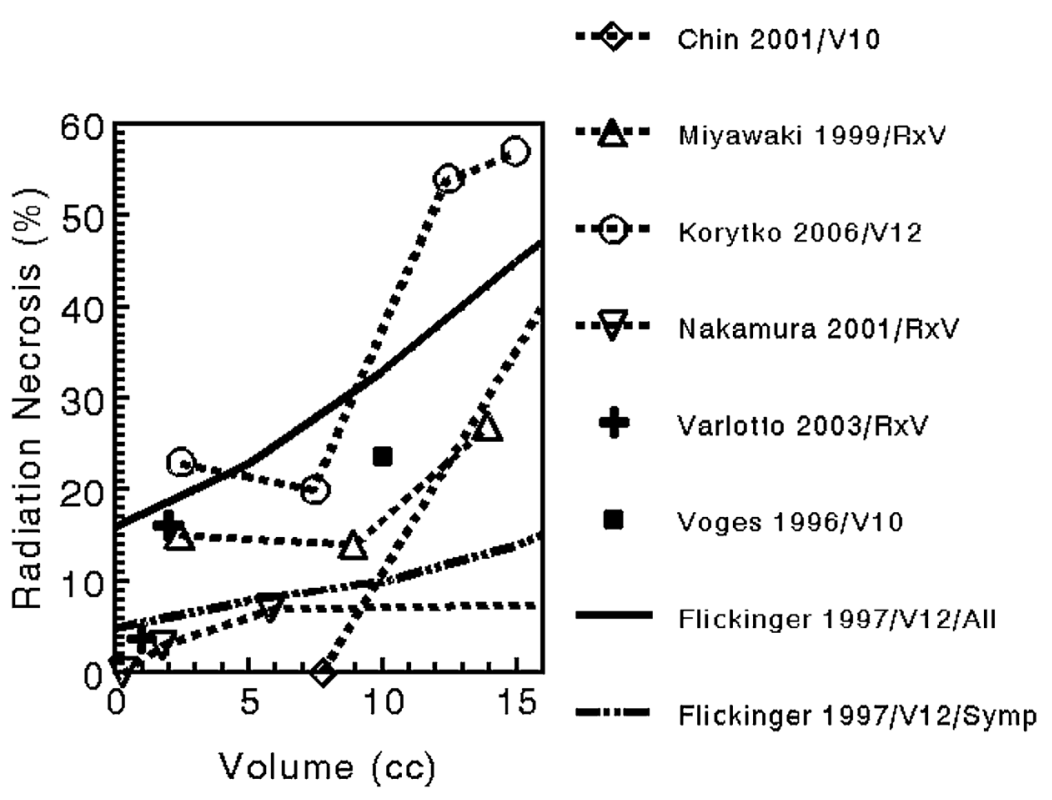

Fig. 1.

Relationship between volume receiving high-dose irradiation and incidence of radiation necrosis in single-fraction stereotactic radiosurgery. Studies differed in their completeness of follow-up, definition of volume, and definition of radiation necrosis. Graph based on data presented in Table 1. Volume plotted as a point, representing mid-point of volume range. $\mathrm{V}_{10}=$ volume receiving $10 \mathrm{~Gy} ; \mathrm{V}_{12}=$ volume receiving $12 \mathrm{~Gy} ; \mathrm{RxV}=$ treatment volume. Flickinger data is shown for patients with either radiologic or symptomatic evidence of necrosis (marked as "All"), or only those with symptomatic necrosis (Symp). The other authors' data refers to symptomatic necrosis. 

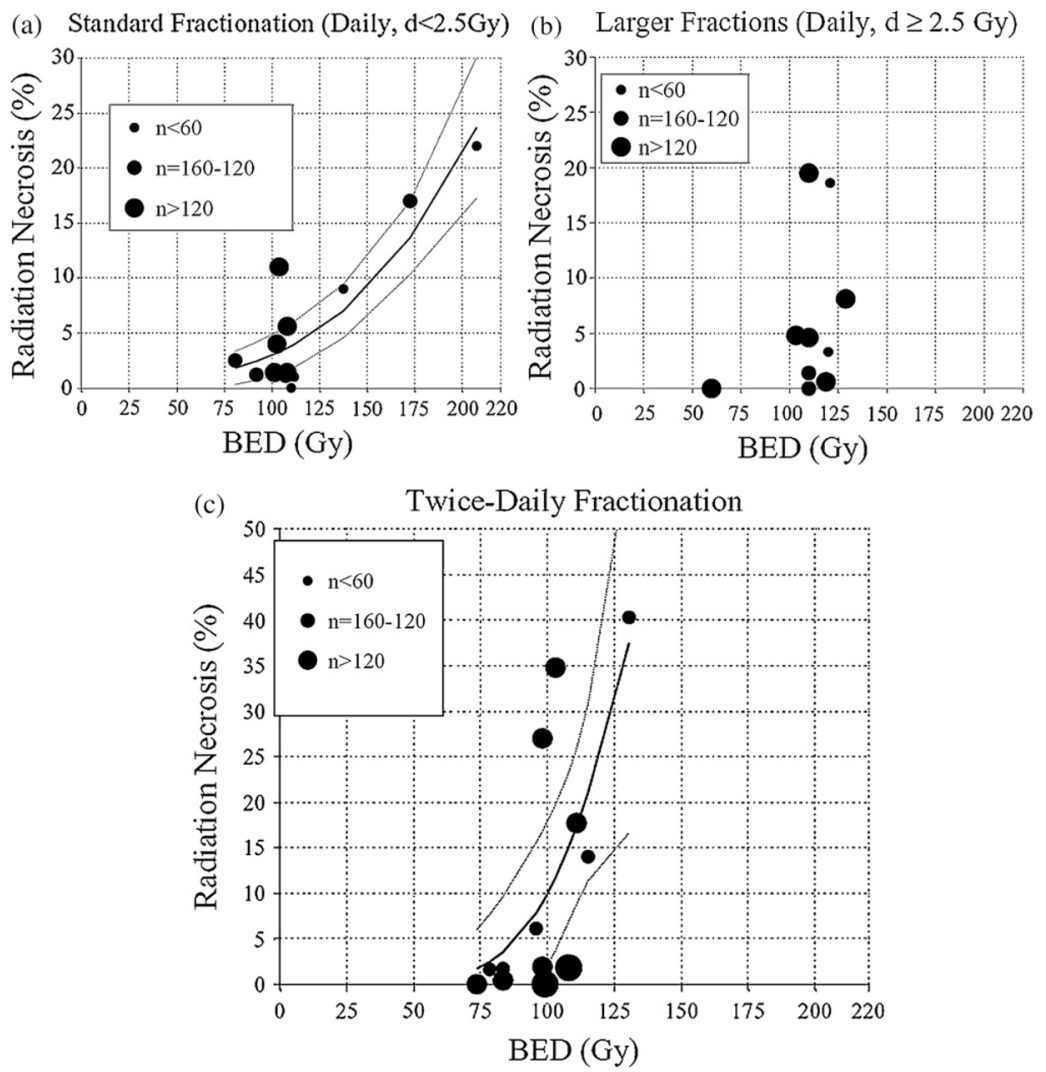

Fig. 2.

Relationship between biologically effective dose (BED) and radiation necrosis after fractionated radiotherapy. Fit was done using nonlinear least-squares algorithm using Matlab software (The MathWorks, Natick, MA). Nonlinear function chosen was probit model (similar functional form to Lyman model). Dotted lines represent 95\% confidence levels; each dot represents data from specific study (Table 2), $\mathrm{n}=$ patient numbers as shown. (a) Fraction size $<2.5 \mathrm{~Gy}$; (b) fraction size $\geq 2.5 \mathrm{~Gy}$ (data too scattered to allow plotting of "best-fit" line); and (c) twice-daily radiotherapy. 


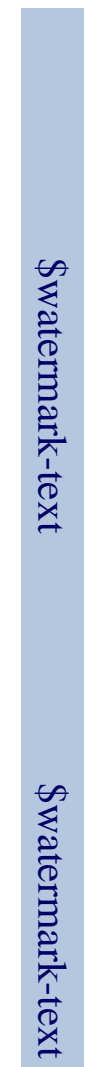

Lawrence et al.

Page 12

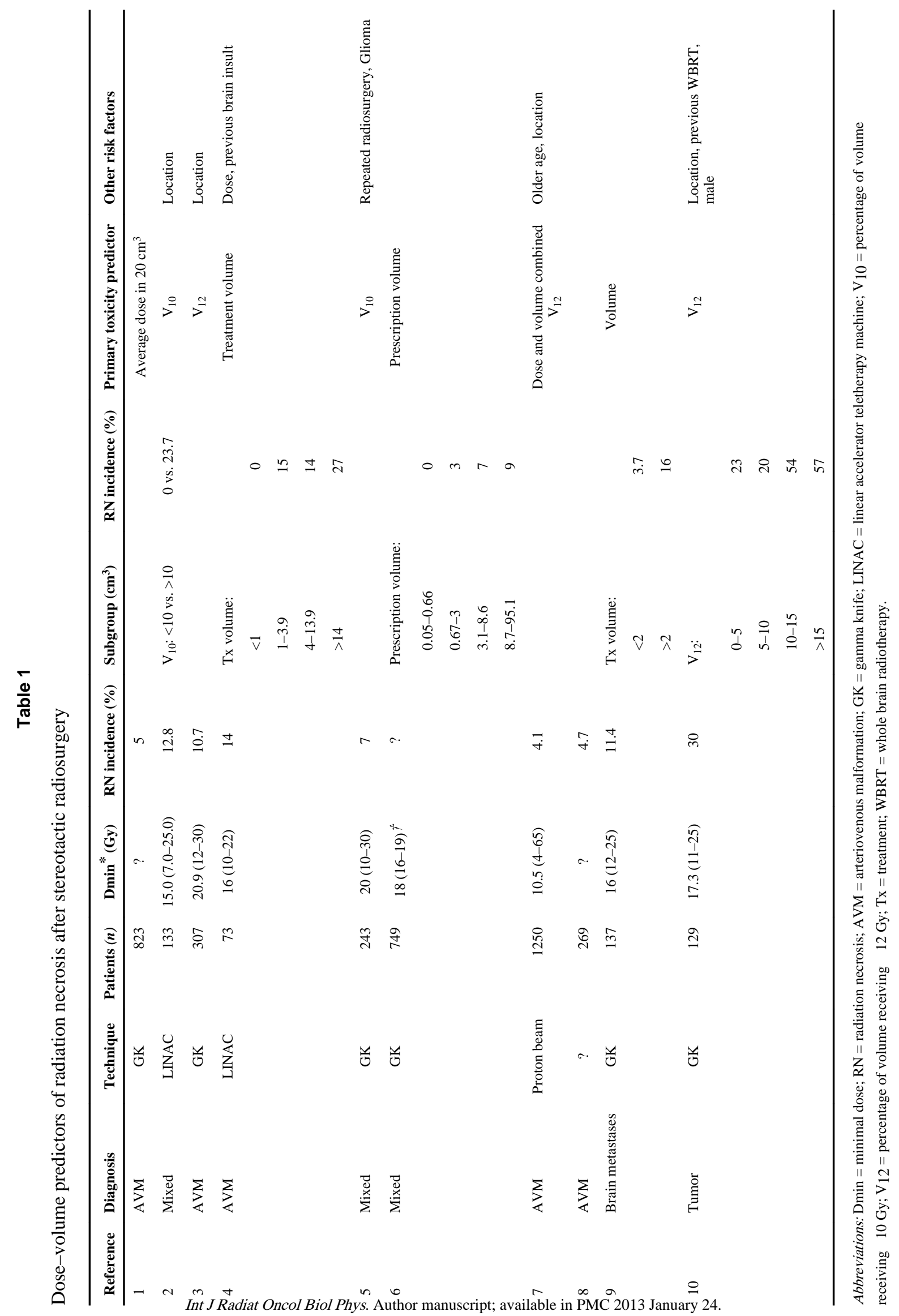




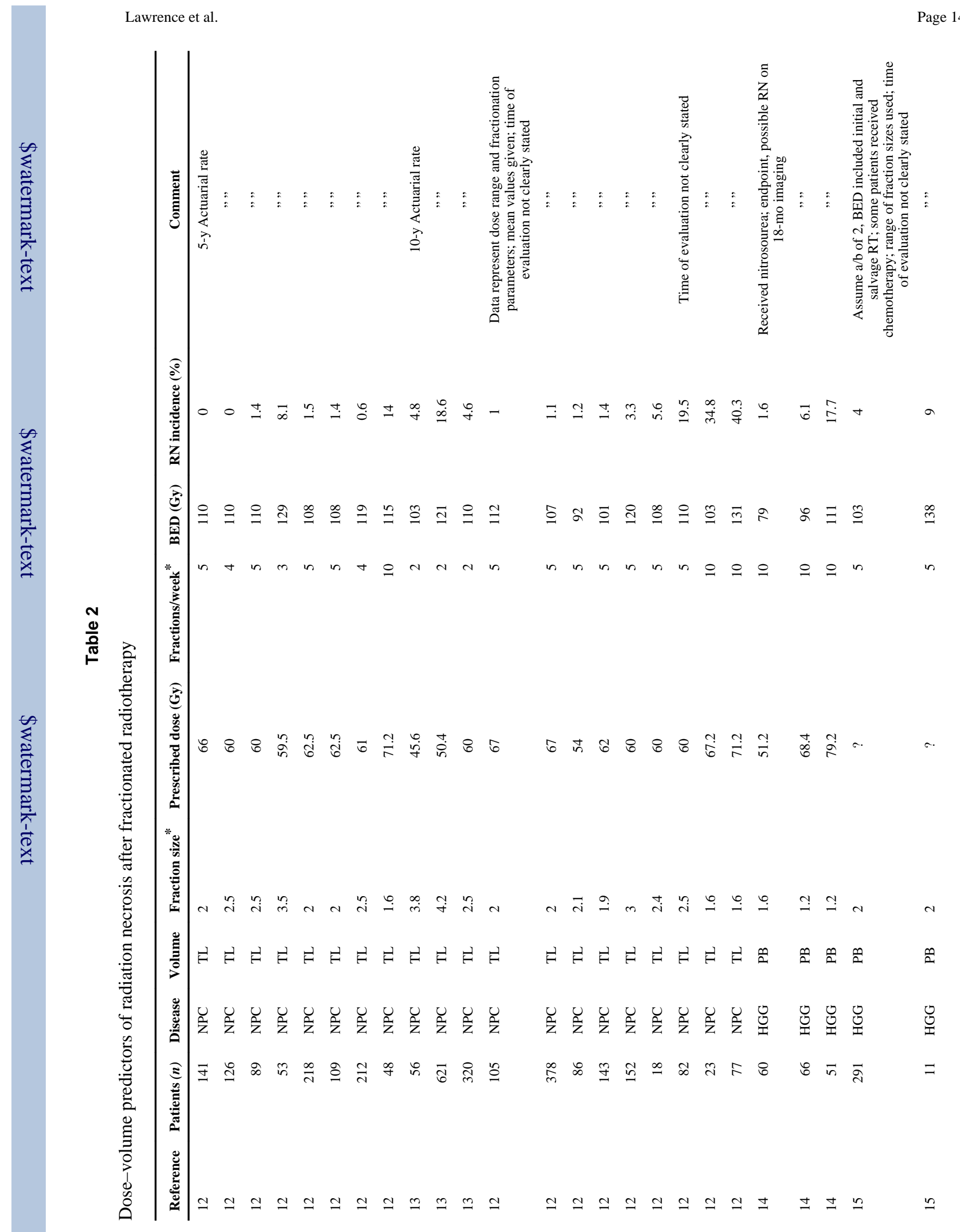

Int J Radiat Oncol Biol Phys. Author manuscript; available in PMC 2013 January 24. 


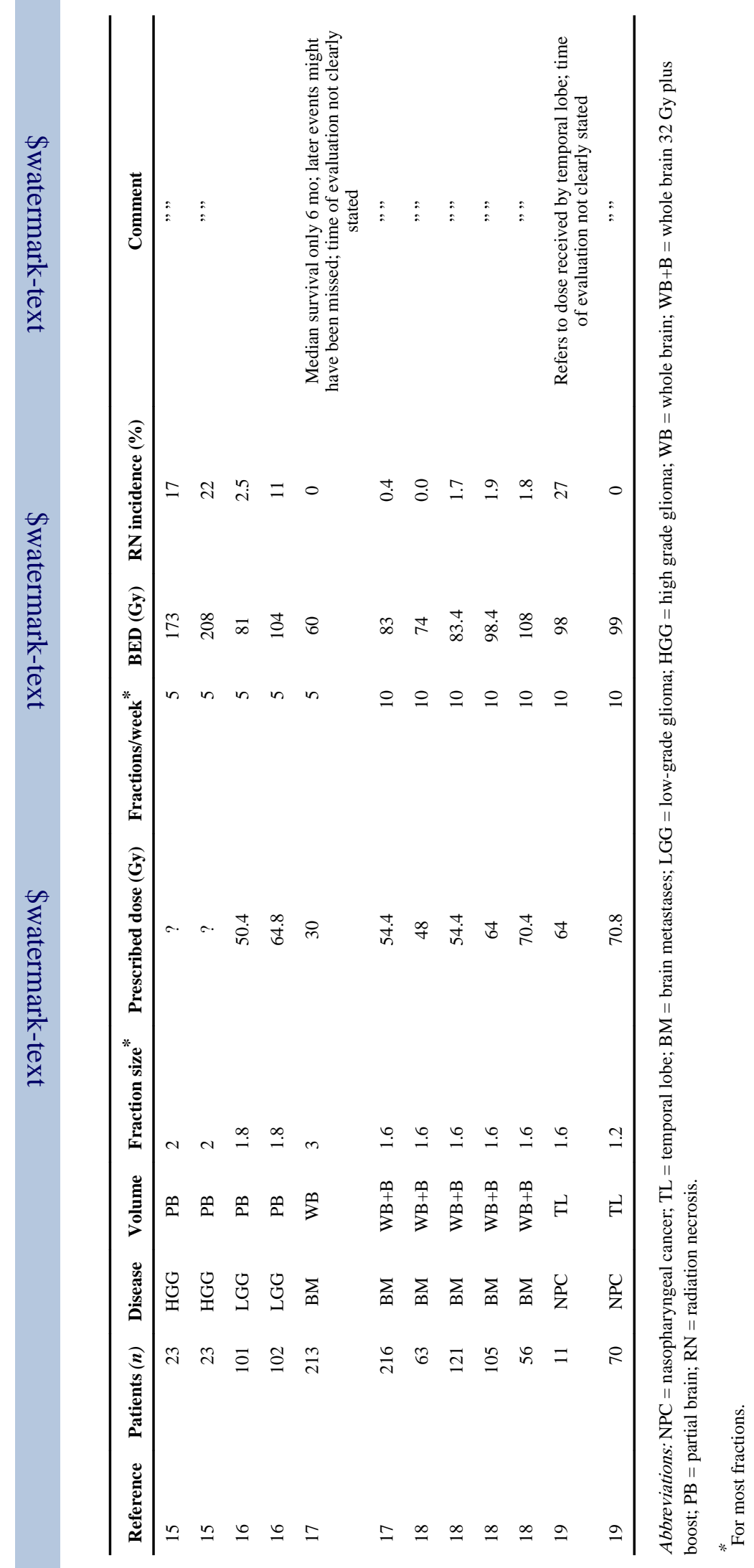

Int J Radiat Oncol Biol Phys. Author manuscript; available in PMC 2013 January 24. 